$$
\text { CONF-960569--18 }
$$

GA-A22353

\title{
CHARACTERISTICS OF THE SCRAPE-OFF LAYER IN DIII-D HIGH-PERFORMANCE NEGATIVE CENTRAL MAGNETIC SHEAR DISCHARGES
}

by

C.J. LASNIER, R. MAINGI, A.W. LEONARD, S.L. ALLEN,

D.A. BUCHENAUER, K.H. BURRELL, T.A. CASPER, J.W. CUTHBERTSON, M.E. FENSTERMACHER, D.N. HILL, R.A. JONG, L.L. LAO, E.A. LAZARUS, R.A. MOYER, T.W. PETRIE, G.D. PORTER, B.W. RICE, B.W. STALLARD, T.S. TAYLOR, and D.G. WATKINS

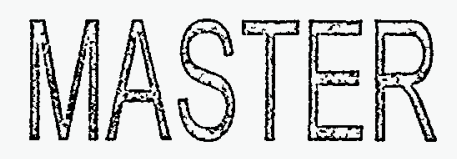

NISTRIITTON OF THIS DOCUMENT IS UNLMITED OCTOBER 1996

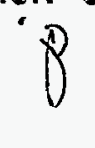




\section{DISCLAIMIER}

Portions of this document may be illegible in electronic image products. Images are produced from the best available original document. 


\section{DISCLAIMER}

This report was prepared as an account of work sponsored by an agency of the United States Government. Neither the United States Government nor any agency thereof, nor any of their employees, makes any warranty, express or implied, or assumes any legal liability or responsibility for the accuracy, completeness, or usefulness of any information, apparatus, product, or process disclosed, or represents that its use would not infringe privately owned rights. Reference herein to any specific commercial product, process, or service by trade name, trademark, manufacturer, or. otherwise, does not necessarily constitute or imply its endorsement, recommendation, or favoring by the United States Government or any agency thereof. The views and opinions of authors expressed herein do not necessarily state or reflect those of the United States Government or any agency thereof. 


\title{
CHARACTERISTICS OF THE SCRAPE-OFF LAYER IN DIII-D HIGH-PERFORMANCE NEGATIVE CENTRAL MAGNETIC SHEAR DISCHARGES
}

\author{
by \\ C.J. LASNIER, ${ }^{\dagger}$ R. MAINGI, ${ }^{\ddagger}$ A.W. LEONARD, S.L. ALLEN,, \\ D.A. BUCHENAUER, $\diamond$ K.H. BURRELL, T.A. CASPER, $\dagger$
}

J.W. CUTHBERTSON, $\triangle$ M.E. FENSTERMACHER, † D.N. HILL, † R.A. JONG, † L.L. LAO, E.A. LAZARUS, £ R.A. MOYER, $\triangle$ T.W. PETRIE, G.D. PORTER, ${ }^{\dagger}$ B.W. RICE, B.W. STALLARD, † T.S. TAYLOR, and D.G. WATKINS\#

This is a preprint of a paper to be presented at the 12th International Conference on Plasma Surface Interactions in Controlled Fusion Devices, May 20-24, 1996, Saint-Raphael, France and to be published in the Proceedings.

$$
\begin{aligned}
& †_{\text {Lawrence Livermore National Laboratory }} \\
& \text { ҒOak Ridge Associated Universities } \\
& \text { `Sandia National Laboratories, Livermore } \\
& \Delta \text { University of California, San Diego } \\
& \text { \#Oak Ridge National Laboratory } \\
& \text { ESandia National Laboratories, Albuquerque }
\end{aligned}
$$

Work supported by the U.S. Department of Energy

under Contract Nos. DE-AC03-89ER51114, W-7405-ENG-48, DE-AC05-96OR22464, DE-AC04-94AL85000, and Grant No. DE-FG03-95ER54294

GA PROJECT 3466 OCTOBER 1996 


\begin{abstract}
In this paper we present measurements of the global power and particle balance in the high-performance phase of negative central magnetic shear (NCS) discharges and compare with reference $\mathrm{VH}$-mode discharges. The principal differences observed are that NCS has a much lower fraction of the total input power flowing into the boundary, less core radiation, and larger rate of stored energy increase as a fraction of total power. Scrape-off layer (SOL) temperature and divertor heat flux profiles, and radiation profiles at the midplane, are similar to VH-mode. Due to the good core particle confinement and efficient fueling by neutral beam injection (NBI), with little gas puffing, the gas load on the walls and the recycling are very low during the NCS discharges. This results in a rate of density rise relative to beam fueling at the $\mathrm{L}$ to $\mathrm{H}$ transition time which is $1 / 3$ of the value for $\mathrm{VH}$ transitions, which is in turn $1 / 2$ that for L-to-ELMing-H-mode transitions.
\end{abstract}




\section{INTRODUCTION}

In this paper we discuss measurements of global power and particle balance in negative central magnetic shear (NCS) discharges in DIII-D. These discharges are of great interest because they have produced very high performance (good confinement, high neutron rates) in DIII-D [1, 2], TFTR [3], and JT-60U [4] and show promise in reducing the cost and size of tokamak fusion reactors. JET has begun a study of NCS discharges in collaboration with DIII-D.

Magnetic shear is defined as $S=(2 \mathrm{~V} / \mathrm{q})(\mathrm{dq} / \mathrm{dV})$ where $\mathrm{q}$ is the safety factor and $\mathrm{V}$ is the volume enclosed by a flux surface [2]. In an NCS discharge, this quantity is negative for the central flux surfaces. Control of the $q$ profile has potential for increased $\beta$, reduced external current drive requirement, and improved confinement [5]. These discharges produce increased neutron rates, high ion temperatures $(20 \mathrm{keV})$, and reduced particle and energy transport in the NCS portion of the discharge.

The NCS discharges in DIII-D have reduced core turbulence and transport [6], and have hollow $Z_{\text {eff }}$ profiles compared to standard positive-shear discharges, but similar to VH-mode

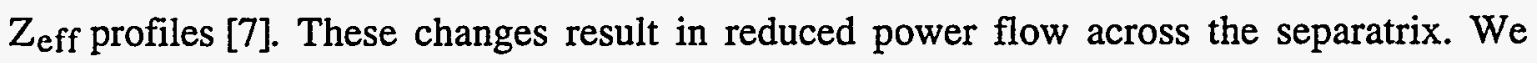
compare SOL characteristics of two types of discharges: NCS, and VH-mode with a monotonically increasing $q$ profile [8]. Both VH-mode and the NCS high-confinement regime are high-performance phases during which particle and energy confinement increase. We produce NCS discharges using early NBI, which causes increased core temperature and delays the penetration of plasma current to the axis. In some discharges with the highest neutron rates, the shear has weakened by the time of the high-performance phase. The shear remains negative or only slightly positive over part of the profile, but not necessarily in the center.

In DIII-D, the highest performance phase of the NCS discharges is ELM-free, similar to standard VH-modes formed with early beam injection. The NCS discharges have been formed with either an edge density profile similar to $\mathrm{H}$-mode ( $\mathrm{H}$-mode edge) or a more gradual edge density gradient characteristic of L-mode (L-mode edge), and in single or double-null. All exhibit high performance. However, the NCS L-modes are predominantly magnetically upshifted double nulls or inner-wall limited, providing little data from our boundary diagnostics located mainly in the lower divertor. (Magnetic upshift puts the lower $\mathrm{X}$-point outside the separatrix.) The $\mathrm{H}$-mode discharges were more balanced magnetically. The L-mode plasmas also exhibit more disruptions due to pressure peaking on axis. Here we 
will concentrate on double-null NCS discharges with $\mathrm{H}$-mode edges. We examine the fraction of the total input power $\left(\mathrm{P}_{\mathrm{in}}\right)$ which crosses the separatrix and is radiated in the SOL or conducted to the divertor plates. The global particle balance during the NCS discharges at the time of the $\mathrm{L}$ to $\mathrm{H}$ transition and during the high-performance phase is compared.

The SOL parameters as measured by Thomson scattering during NCS discharges are compared with corresponding VH-mode data. The spatial distribution of radiation from the plasma core and edge bolometry are also compared. The divertor heat flux profiles measured using IR cameras are examined. 


\section{POWER BALANCE}

We measure radiated power using arrays of bolometers at two toroidal locations. The total radiated power (assuming toroidal symmetry, and constant radiation along closed flux surfaces) is added to the total power conducted to the divertor plates measured with IR cameras (again assuming toroidal symmetry) along with calculations of the rate of change of stored energy ( $d W / d t$ ) from magnetic measurements. This sum is compared with $P_{\text {in }}$ from NBI and Ohmic heating. These quantities for an NCS discharge are shown in a stacked plot in Fig. 1, with the neutron rate, thermal confinement time, and line-integrated density.

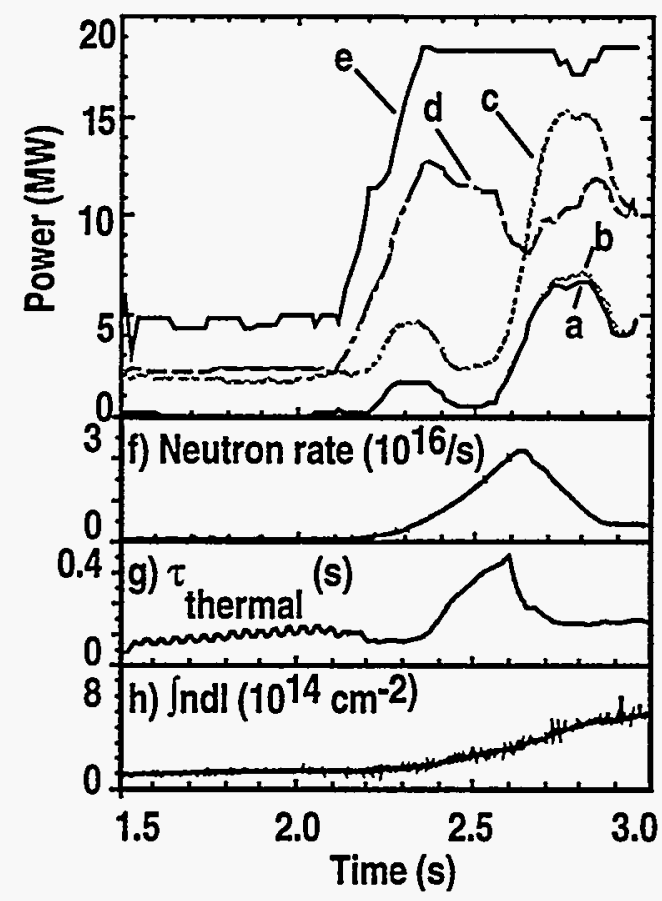

Fig. 1. Stacked plot of power balance versus time. Each curve a-d represents the sum of the lesser lettered curves plus an additional contribution to the power loss inventory. All curves are versus time. (a) Total power at the lower divertor plate. (b) Total at the upper divertor plate added. (c) Total radiated power added. (d) rate of change of stored energy $\mathrm{dW} / \mathrm{dt}$ added. Curve (d) is the sum of all the individual power loss contributions in (a), (b), (c), and (d). Since dW/dt becomes negative shortly after $2.6 \mathrm{~s}$, curve (d) falls below curve (c). Curve (d) may be compared with $(e) P_{\text {in }}$. (f) Neutron rate. (g) Thermal confinement time. (h) Line-averaged density along a vertical chord. Ohmic input power is approximately $1 \mathrm{MW}$, and the rest is NBI. Toroidal field is 2.2 Tesla, and plasma current flat-top is 2.2 MA.

This discharge has the highest $Q_{D D}$ value obtained in DIII-D to date $\left(Q_{D D}=0.0015\right)$, with an equivalent $Q_{D T}^{e q}=0.32$ [1]. The high-performance phase is during the ramp in neutron rate, and has a density increase due to the increased fueling from beams and improved particle 
confinement in the core. A large part of $\mathrm{P}_{\text {in }}$ during this phase is retained in the core plasma as stored energy, as shown in the figure by the large increase in dW/dt after $2.1 \mathrm{~s}$ and the proportionally much smaller increases in radiated and conducted power. As the plasma later approaches a $\beta$ limit, low- $n$ MHD activity begins and core confinement decreases, the neutron production rate peaks and begins to decrease, and both radiation and divertor heat flux increase greatly. NCS was established using early beam injection, but before the high performance phase, the negative shear region had moved out radially (Fig. 2). The performance of this discharge is discussed in another publication [1].

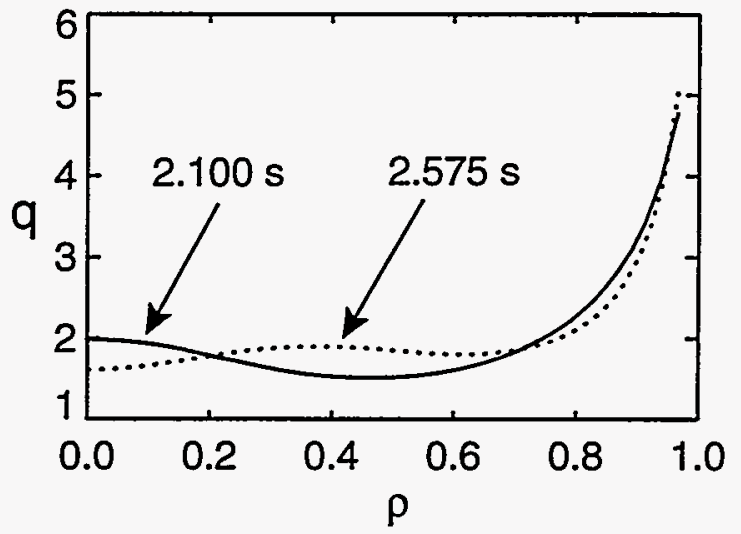

Fig. 2. Safety factor profiles, $q(r)$ early in the 87977 discharge and near $2.5 \mathrm{~s}$ during the high performance phase.

We account for at most $65 \%$ of $\mathrm{P}_{\text {in }}$ in the high performance phase of this discharge. This is lower than the typical value of up to $85 \%$ for lower single-null ELMing $\mathrm{H}$-mode. Some power escapes to the inner wall which was not monitored here (less than $10 \%$ of $P_{\text {in }}$ in other discharges). The radiated power calculation shown in Fig. 1 is less accurate than the calculation for a single time-slice discussed below, which usually adds another 10\%$20 \%$ of the radiated power. The remaining discrepancy may be ascribed to error bars in bolometer $( \pm 15 \%)$, IR camera $( \pm 20 \%)$, and $\mathrm{dW} / \mathrm{dt}( \pm 5 \%)$ measurements, as well as $\mathrm{P}_{\text {in }}$ measurements.

We can examine in more detail how the power loss is distributed at $2.5 \mathrm{~s}$ during the neutron ramp. For this time slice, we have performed a more accurate calculation of total radiated power by using an inversion technique to arrive at the poloidal cross-section of the radiation, and then integrated over the core and SOL separately. Power radiated inside the separatrix but within $20 \mathrm{~cm}$ vertically of an $\mathrm{X}$-point is considered with the SOL radiation, since there is sometimes enhanced radiation near the $\mathrm{X}$-points depending on divertor conditions. These results and similar calculations for several other discharges are shown in Fig. 3. 


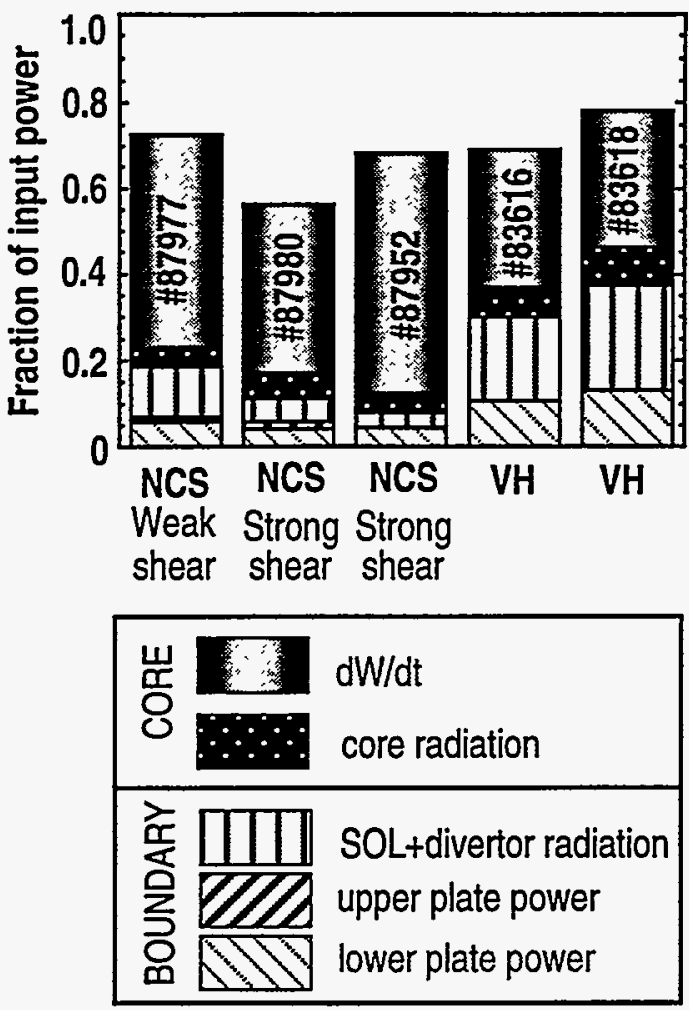

Fig. 3. Stacked bar graph of power distribution during NCS and VH-mode discharges. In the NCS discharges, the power fraction radiated and conducted in the boundary plasma is much lower than in the $\mathrm{VH}$-modes, and the $\mathrm{dW} / \mathrm{dt}$ fraction is larger. Core radiation fraction is also slightly reduced in NCS. Upper divertor plate power data was available for 87977 and 87980 , but the power is so small it is barely visible on the graph. Toroidal field for these discharges was $2.2 \mathrm{~T}$.

This figure shows the power loss components stacked in the same order as in Fig. 1, but with the core and boundary radiation separated. The first discharge (87977) is the same NCS plasma examined in Fig. 1. The next two discharges in Fig. 3 (87980 at $2.7 \mathrm{~s}$ and 87952 at $2.3 \mathrm{~s}$ ) retained strong negative shear through the high performance phase. The last two time slices were taken during the VH-mode period of two discharges (83616 at $2.6 \mathrm{~s}$ and 83618 at $2.5 \mathrm{~s})$. Table 1 shows $\mathrm{P}_{\text {in }}$ and line-integrated densities.

There is considerable variation shown within members of the same class (NCS or VH). The VH-mode shows much larger radiated and conducted power fraction than the NCS, which has a much larger dW/dt fraction. Due to the much lower core transport, the NCS discharges allow much less power to cross into the boundary. This difference holds even for discharges of more nearly equal power levels. This high-performance phase is usually transient in DIII-D, although it has been extended in JT-60U by using rf current drive to control the current profile [4] 


\section{TABLE 1}

$P_{\text {in }}$ and line-integrated density for the discharges in Fig. 3

\begin{tabular}{ccc}
\hline Discharge & $\begin{array}{c}\mathrm{P}_{\text {in }} \\
(\mathrm{MW})\end{array}$ & $\begin{array}{c}\text { Jndl } \\
\left(10^{14} \mathrm{~cm}^{-2}\right)\end{array}$ \\
\hline 87977 & 18.3 & 2.2 \\
97980 & 21.3 & 2.1 \\
97952 & 21.0 & 1.8 \\
83616 & 6.3 & 2.6 \\
83618 & 5.4 & 2.6 \\
\hline
\end{tabular}

In discharges where upper divertor plate power data was available, it was only a small fraction of $P_{\text {in }}$. This is true in general for DIII-D with magnetically balanced discharges and ion $\nabla B$ drift downward [9]. The upper divertor plate heat flux is generally less than one third of the lower divertor heat flux, at least partly because the ion $\nabla \mathrm{B}$ drift ordinarily favors the lower divertor. In the present cases, the upper divertor component is even smaller. 


\section{GLOBAL PARTICLE BALANCE DURING DISCHARGES}

In this section, we examine the global particle balance and wall loading rate near the time of the transition to the enhanced confinement regime. This global particle balance does not distinguish between the divertor plate and other walls. We use "wall" to mean the entire exposed surface, which we expect the divertor surface to dominate. The wall loading of NCS discharges during the current ramp-up phase is qualitatively similar to published data on ohmic ramp-up, i.e., the wall pumps particles during that phase [10]. However, the wall loading is smaller because efficient NBI fueling is initiated and cold gas puffing is terminated early in the discharge, by $t=0.3 \mathrm{~s}$. Thus most of this discussion will focus on the wall loading near the time of the transition to the enhanced confinement regime.

The wall particle loading (pumping) rate during discharges is estimated as the difference between the measured input neutral sources, sinks, and inventory build-up:

$$
S_{\text {wall }}=S_{N B I}+S_{p u f f}-\frac{d N_{e}}{d t}-\frac{d N_{0}}{d t}-S_{c r y o}
$$

where

$$
\begin{aligned}
& S_{N B I}=\text { energetic }+ \text { cold beam particle fueling } \\
& S_{p u f f}=\text { gas puff fueling } \\
& \frac{d N_{e}}{d t}=\text { neutral loss rate due to plasma formation } \\
& \frac{d N_{0}}{d t}=\text { neutral gas buildup rate } \\
& S_{c r y o}=\text { cryopump exhaust rate } \\
& S_{\text {wall }}=\text { wall pump rate }
\end{aligned}
$$

This type of global particle balance has been used previously for DIII-D discharges ([11] and references therein). Typically the wall pumps neutral particles during the plasma current ramp-up, leading to $\sim 10 \%$ fueling efficiency. At the confinement transition, the wall typically supplies particles to the plasma, making the plasma density rise faster than the beam fueling rate [12-14]. The role of the wall particle balance in the density rise phase after beam power is increased to its steady level can be examined via a simplified balance. In this phase of the discharges, $S_{\text {puff }}$ is 0 , and $\frac{d N_{0}}{d t}$ and $S_{c r y o}$ are small and thus neglected $\left(S_{c r y o} / S_{N B I}<\right.$ $10 \%$ ). Eliminating the above terms and dividing Eq. (1) by $S_{N B I}$ yields: 


$$
\frac{S_{w a l l}}{S_{N B I}}=1-\frac{\frac{d N_{e}}{d t}}{S_{N B I}}
$$

If the right-hand-side of Eq. (2) $<0$, i.e. $\frac{d N_{e}}{d t}>S_{N B I}$, the wall is a net source of particles to the discharge, i.e. the wall is outgassing. Typical ELMing H-mode plasmas have the peak $\frac{d N_{e}}{d t} \sim 2-6^{*} S_{N B I}$ in the ELM-free phase following the L-H transition [10,11]. Figure 4 shows a comparison for NCS, VH-mode and ELM-free $\mathrm{H}$-mode discharges. It is evident in all cases that $\frac{d N_{e}}{d t} \sim S_{d N I}$ in the density rise phase of the strongly and weakly reversed shear discharges, whereas $\frac{d N_{e}}{d t} \sim 2-3^{*} S_{N B I}$ for the VH-mode discharge and 5-6 for the ELM-free $\mathrm{H}$-mode discharge. This difference in $\frac{\mathrm{dN}_{\mathrm{e}}}{\mathrm{dt}} / \mathrm{S}_{\mathrm{NBI}}$ can be attributed to the fact that the gas input required to obtain the target discharge at the end of the current ramp-up phase is very low in the reversed shear configurations ( $\sim 30$ Torr-1, $2.1 \times 10^{21}$ atoms), because the target density is lower and because NBI heating and fueling, which is more efficient than gas puffing, comes on earlier to set up the reversed shear configuration. In comparison the gas fuel added during the ramp up phase is 60 Torr-l $\left(4.2 \times 10^{21}\right.$ atoms $)$ for the VH-mode discharge and 90 Torr-1 $\left(6.3 \times 10^{21}\right.$ atoms) for the ELM-free H-mode discharge. Thus there is much less wall loading and saturation of the near surface layers during the current ramp-up phase, leading to a smaller number of particles available for outgassing in the density rise phase. That the wall is effectively removed as a net source of particles is a testament to the extremely low recycling conditions achieved in the negative shear discharges. 

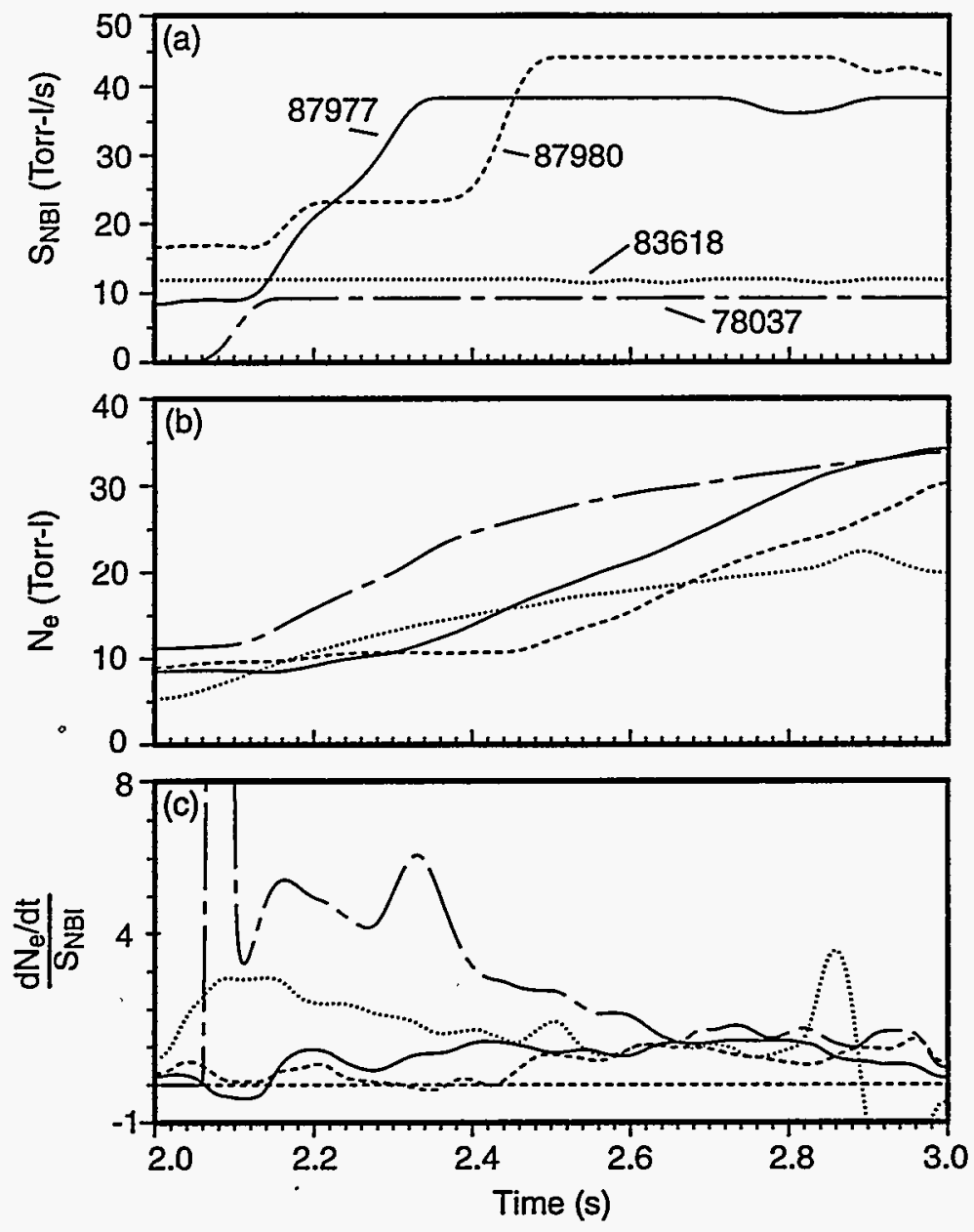

Fig. 4. (a) Neutral beam particle source rate $\left(\mathrm{S}_{\mathrm{NBI}}\right)$ versus time for weak negative shear (87977, solid), strong negative shear ( 87980 , dashed), $\mathrm{VH-mode} \mathrm{positive} \mathrm{shear}$ (83618, dotted) and a reference ELM-free $\mathrm{H}$-mode (78037, dash-dot). The NBI source rate is much higher for the NCS than for the other discharges. (b) Plasma Inventory $\left(N_{e}\right)$ versus time for above discharges. (c) $\frac{d N_{e}}{d t} / S_{N B I}$ for above discharges; note that the ratio for the negative shear discharges $\leq 1$, indicating that the wall is not a net particle source at the onset of the high confinement phase which starts when the density rises. The peak ratio $\sim 3$ for the $\mathrm{VH}$-mode discharge and $\sim 6$ for the ELM-free $\mathrm{H}$-mode discharge, indicating that the wall is a net source during the density rise phase. The artifact from 2.06-2.10 $\mathrm{s}$ for the ELM-free $\mathrm{H}$-mode discharge occurs because the NBI only turns on near that time. 


\section{PROFILES}

An examination of midplane radiation profiles from bolometer inversions shows no qualitative differences among the discharges examined here, except that the highest power discharges have increased radiation outside $\rho=0.8$. The electron temperature gradients near the separatrix measured by Thomson scattering are quite similar for the NCS and VH discharges considered, in spite of the wide variation in $\mathrm{P}_{\mathrm{in}}$. The edge electron density profiles for the NCS discharges (also from Thomson) show some differences in gradient from VH-mode, which may be mainly due to uncertainty in the magnetic equilibrium reconstruction. The divertor heat flux profile widths from infrared camera measurements mapped to the midplane are similar to profiles for other ELM-free discharges, about $30 \%$ narrower than ELMing H-mode. 


\section{SUMMARY}

The primary distinction between the NCS discharges and similar VH discharges is the reduced power flowing into the boundary, because of good core confinement and large positive dW/dt. Core radiation is also slightly reduced. The NCS radiation profiles at the midplane, the electron temperature profiles near the separatrix, and the divertor heat flux profiles mapped to the midplane are similar to VH-mode.

Due to the good core particle confinement and efficient fueling by beams, with little gas puffing, the gas load on the walls and the recycling are very low during the NCS discharges. This results in a $\frac{d N_{e}}{d t} / S_{N B I}$ at the $\mathrm{L}$ to $\mathrm{H}$ transition time which is $1 / 3$ of the value for $\mathrm{VH}$ transitions, which is in turn $1 / 2$ that for L-to-ELMing-H-mode transitions.

The transient nature of the high-performance phase urges caution in applying these results. Experiments are planned in the near future to lengthen the high-performance phase by using pumping to control the density, to maintain neutral beam penetration. 


\section{REFERENCES}

[1] Lazarus, E.A., Navratil, G., Greenfield, C.M., et al., to be submitted to Phys. Rev. Lett. (1996).

[2] Rice, B.W., Burrell, K.H., Lao, L.L., et al., Phys. Plasmas 3 (5), 1983 (1986)

[3] Levinton, F.M., Zarnstorff, M.C., Batha, S.H., et al., to be published in Phys. Rev. Lett.

[4] Kimura, H. and the JT-60U Team, Phys. Plasmas 3(5), 1943 (1996)

[5] Strait, E.J., Lao, L.L., Mauel, M.E., et al., Phys. Rev. Lett. 75(24), 4421 (1995).

[6] Lao, L.L., Burrell, K.H., Casper, T.S., et al., Phys. Plasmas 3(5), 1951 (1996)

[7] Whyte, D.G. et al., "Measurement and Verification of $Z_{\text {eff }}(r)$ Using Charge Exchange Recombination Spectroscopy on DIII-D", to be submitted to Nucl. Fusion.

[8] Jong, R.A., IAEA Tech. Comm. Meeting on H-mode Phys./U.S.-Japan Workshop on H-mode Phys./5th Workshop on H-mode Phys., Princeton, New Jersey, USA, 1995. To be published in Plasma. Phys. Contr. Fusion.

[9] Lasnier, C.J., Hill, D.N., Petrie, T.W., et al., "Target Plate Heat Flux in Diverted DIII-D Tokamak Discharges," submitted to Nuclear Fusion (1996).

[10] Mahdavi, M.A. et al., Proc. of 20th Euro. Conf. on Contr. Fusion and Plasma Physics European Physical Society, Petit-Lancy, Switzerland, Lisboa, Portugal, 1993, 17C, 647.

[11] Maingi, R. et al., Nucl. Fusion 36, 245 (1996).

[12] Mahdavi, M.A. et al., Proc. of 16th Euro. Conf. on Contr. Fusion, Venice, 1989, I, 249.

[13] Jackson, G.L. et al., J. Vac. Sci. Technol. A 10, 1244 (1992).

[14] Jackson, G.L., Taylor, T.S., and Taylor, P.L., Nuclear Fusion 30, 2305 (1990).

[15] Rensink, M.E. et al., Phys. Fluids B 5, 2165 (1993). 


\section{ACKNOWLEDGMENT}

Work supported by U.S. Department of Energy under Contract Nos. DE-AC0389ER51114, W-7405-ENG-48, DE-AC05-96OR22464, DE-AC04-94AL85000, and Grant No. DE-FG03-95ER54294. 